
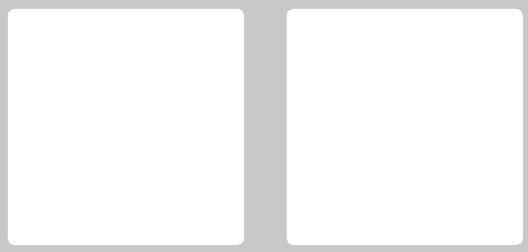

\title{
A CONSTRUÇÃO DE CENÁRIOS PARA O ALINHAMENTO ENTRE FORMULAÇÃO E IMPLEMENTAÇÃO DA ESTRATÉGIA
}

\section{Scenario Building for alignment between Strategy Formulation and Implementation}

\section{Daiane Aparecida de Melo Heinzen}

Professora do curso de Administração. Instituto Federal de Santa Catarina (IFSC) - Campus Jaraguá do Sul. Jaraguá do Sul, SC. Brasil. e-mail:daimheinzen@gmail.com

\section{Sidnei Vieira Marinho}

Mestre em Administração. Universidade do Vale do Itajai (UNIVALI) Jaraguá do Sul, SC. Brasil.

e-mail:sidnei@univali.br

\section{RESUMO}

O gap existente entre formulação e implementação da estratégia é evidenciado nos baixos índices de implementação da estratégia registrados em relatos de pesquisas ao longo dos anos. Diante disso, este artigo tem como objetivo analisar a contribuição dos Métodos de Cenários para o alinhamento entre a formulação e implementação da estratégia por meio de um levantamento teórico do tema 'cenários' relacionado à 'formulação e implementação da estratégia' e 'alinhamento estratégico. A partir da análise dos estudos teóricos e empíricos percebeu-se a relevância dos Métodos de Cenários para a gestão estratégica das organizações, os quais podem contribuir para o alinhamento entre a formulação e implementação da estratégia. Os resultados mostram ainda que todos os Métodos de Cenários apresentados neste artigo compartilham características em comum, e que a principal diferença entre os autores é a ênfase dada a cada etapa do processo. Diante disso, as organizações podem optar por um Método de Cenário que melhor se adapte a sua realidade e fazer uso durante seu processo estratégico a fim de contribuir para o alinhamento entre a formulação e implementação da estratégia.

Palavras-chave: Métodos de Cenários. Formulação da Estratégia. Implementação da Estratégia. Alinhamento Estratégico.

\section{ABSTRACT}

The gap that exists between strategy formulation and implementation is evidenced in the low implementation rates reported in research reports over the years. Thus, this article has as objective analyze the contribution of Scenarios Methods for alignment between strategy formulation and implementation through a theoretical research theme 'scenarios' related to 'strategy formulation and implementation' and 'strategic alignment'. From the analysis of theoretical and empirical studies we realized the relevance of Scenarios Methods for strategic management of organizations, which may contribute to the alignment between the strategy formulation and implementation. It was also found that all the Scenarios Methods in this article share features in common, and that the main difference between the authors is the emphasis given to each step of the process. Thus, organizations can opt for a Scenario Method that best suits your reality and make use during your strategic process in order to contribute to the alignment between strategy formulation and implementation.

Keywords: Scenarios Methods. Strategy Formulation. Strategy Implementation. Strategic alignment. 


\section{INTRODUÇÃO}

A falta de êxito entre a formulação e implementação da estratégia têm sido uma preocupação crescente e foco de estudos no campo acadêmico e empresarial, levando às organizações a falta de informações de quanto às ações estratégicas contribuem para o alcance dos objetivos e metas organizacionais.

Levando-se em consideração que a implementação eficaz da estratégia é vital para o sucesso organizacional, estudos investigam os obstáculos para o alinhamento entre formulação e implementação da estratégia a fim de contribuir com o conhecimento acadêmico e organizacional.Cocks (2010) e Gandellini, Pezzi e Venanzi (2013), expõem que o sucesso organizacional requer constante alinhamento entre a formulação da estratégia e sua implementação.

Prieto, Carvalho e Fischmann (2009, p. 322) definem alinhamento como: "tanto um processo como um resultado - uma dinâmica que procura ajustar a organização externamente em relação ao seu ambiente de atuação, por meio da formulação da estratégia e internamente buscando um todo coeso entre a estratégia, recursos e os processos gerenciais".

Adicionalmente, segundo Prieto (2011), o alinhamento interno e externo é complementar, sendo indissociável na realidade organizacional, corroborando autores como: Hambrick e Cannella (1989); Bertero, Vasconcelos e Binder (2003); Martin (2010) quando afirmam que a separação 'inútil' entre formulação e implementação pode levar a organização ao fracasso. Desta forma, o alinhamento entre a formulação da estratégia e sua implementação, talvez seja condição essencial no atual ambiente competitivo, complexo, turbulento e de múltiplas incertezas em que as organizações atuam, com o objetivo de manterem-se competitivas. Diante disso, Fink, Siebe e Kuhle (2004) e Moritz, Nunes e Pereira (2008) expõe que o uso de Métodos de Cenários pode apoiar tanto o processo de formulação quanto implementação da estratégia, contribuindo para reduzir as incertezas do ambiente organizacional, melhoria da tomada de decisão e o distanciamento entre a formulação e implementação da estratégia.

Considerando a importância e a crescente utilização dos Métodos de Cenários na gestão estratégica, apresenta-se a questão principal que irá nortear esta pesquisa: qual a relevância dos Métodos de Cenários na formulação e implementação da estratégia nas organizações? Diante disso, o presente artigo tem como objetivo analisar a contribuição e relevância dos Métodos de Cenários para o alinhamento entre a formulação e implementação da estratégia por meio de um levantamento teórico. O estudo demonstra sua relevância ao relacionar as variáveis estudadas 'cenários', 'formulação e implementação da estratégia' e 'alinhamento estratégico', pois se observa uma lacuna no campo científico acerca da correlação destes temas. Este estudo contribui ainda com o estado da arte sobre o tema ao apresentar os principais Métodos de Cenários e uma análise crítica das principais características destes, bem como para compreensão das dificuldades de implementação da estratégia, considerando a escassez de pesquisas relativas a problemática de implementação nas organizações.

\section{REFERENCIAL TEÓRICO}

\subsection{Formulação da estratégia}

Para Hambrick e Cannella (1989); Bertero et al. (2003); Mintzberg (2004) e Martin (2010) a implementação da estratégia deve ser considerada durante o processo de formulação, considerando que a separação 'inútil' entre formulação e implementação não contribui em nada com a organização e ainda poderá levar ao fracasso. Para Hrebiniak (2008) e Prieto et al. (2009), a formulação e implementação da estratégia são relacionadas e interdependentes, em que cada atividade pode ser diferenciada e discutida separadamente. Porém, na lógica, segundo os autores, a implementação segue a formulação, considerando que não se pode implementar algo antes do planejamento. Ainda, segundo Hrebiniak (2008), essa interdependência entre formulação e implementação da estratégia sugere que a conexão entre os 'planejadores' e 'executores' melhore a probabilidade de sucesso da implementação.

Cocks (2010) expõe que o sucesso organizacional requer constante conexão entre a formulação da estratégia e sua implementação, ou seja, a formulação da estratégia precisa 'inputs' do nível operacional para trazer 'insights' de confiança sobre as capacidades 
organizacionais e restrições de recursos. Por fim, Gandellini et al. (2013, p.10) expõem que "a criação de estratégias eficazes conectam as pessoas em uma organização que formulam estratégias com as pessoas que implementam estratégias". Para os autores, o desenvolvimento da estratégia é um pré-requisito para sua implementação, porém, na prática, a separação entre o 'pensar' e 'agir' é caracterizada pelo fato dos gerentes formularem a estratégia e os níveis mais baixos serem responsáveis pela sua implementação.

Existem trabalhos, envolvendo muitos métodos e escolas de pensamento sobre a formulação e desenvolvimento da estratégia. Entre os de maior destaque incluem-se as abordagens de posicionamento (associada a Michel Porter); visão baseada em recursos (resorce-based-view), competências essenciais (core competencies), gestão baseada em valor (value-based management), lucro oriundo do núcleo (profit-from-the core), oceano azul (blue ocean), estratégia emergente (emergent estrategy), co-criação de experiências (experience cocreation) e inovação disruptiva (disruptive inovation) (KAPLAN; NORTON, 2008).

Destaca-se também às dez escolas de formulação da estratégia da obra Safári de Estratégia de Mintzberg, Ahlstrand e Lampel (2010), são elas: escola de design; escola do planejamento; escola do posicionamento; escola empreendedora; escola cognitiva; escola de aprendizado; escola de poder; escola cultural; escola ambiental e escola de configuração.

A seguir, apresentam-se os temas 'alinhamento estratégico' e 'implementação da estratégia', os quais estão inter-relacionados com a formulação da estratégia.

\subsection{Alinhamento estratégico}

São encontrados alguns sinônimos para o termo 'Alinhamento', como: ajuste, (do inglês, fit) (VENKATRAMAN; CAMILLUS, 1984); coalinhamento (VENKATRAMAN; PRESCOTT, 1990); congruência (SEMLER, 1997), entre outros, levando em consideração sua falta de consenso na literatura.

De acordo com Venkatraman e Camillus (1984), o conceito de alinhamento é investigado a partir de três categorias: alinhamento externo - refere-se ao ambiente competitivo da organização o qual busca alinhar a estratégia às variáveis externas, considerando a formulação da estratégia; alinhamento interno - está relacionado à mobilização dos recursos visando alinhar as estratégias as variáveis internas (estrutura, sistema de gestão e cultura organizacional) para implementação da estratégia formulada; e o alinhamento integrado (externo e interno). $\mathrm{O}$ alinhamento é classificando ainda quanto ao conteúdo (elementos a serem alinhados com a estratégia) e quanto ao processo (como realizar o alinhamento). A essência de suas raízes teóricas encontra-se na literatura de implementação da estratégia e mudança organizacional (PRIETO, 2011; VENKATRAMAN; CAMILLUS, 1984).

Pesquisas acerca do alinhamento externo tem considerado a integração das capacidades (FUCHS; MIFFLIN; MILLER; WHITNEY, 2000); alinhamento dinâmico (ZAJAC; KRAATZ; BRESSER, 2000) e inércia organizacional (SIGGELKOW, 2001), dentre outras. $\mathrm{E}$ as pesquisas relacionadas ao construto alinhamento interno têm sido conduzidas a partir do alinhamento vertical (AV) e alinhamento horizontal (AH). O alinhamento vertical está relacionado com a configuração de estratégias, objetivos, planos de ação e decisões nos diversos níveis organizacionais. Já o alinhamento horizontal, pode ser definido em termos de integração entre as funções e dentro das funções, não sendo comum dentro das organizações (KATHURIA; JOSHI; PORTH, 2007).

Em síntese, estudos mostram a relevância do alinhamento estratégico para as organizações que buscam a excelência (MILES; SNOW; 1984). O alinhamento também contribui de forma significativa para a implementação da estratégia (HAMBRICK; CANELLA, 1989; HREBINIAK, 2006; KAPLAN; NORTON, 2008); para aumentar a vantagem competitiva da organização (COLLINS; MONTGOMERY, 1998); e para melhorar o desempenho organizacional (PRIETO, 2011). Enfim, alinhamento estratégico é tema central para a gestão estratégica organizacional (VENKATRAMAN; CAMILLUS, 1984).

\subsection{Implementação da estratégia}

A implementação da estratégia é uma fonte de insatisfação para muitas empresas (NOBLE, 1999a); um processo organizacional multifacetado e comple- 
xo (NOBLE, 1999b; OKUMUS, 2003); um fator de impacto no sucesso da organização (RAPS, 2004); é a fase que concentra as principais fraquezas do processo de gestão estratégica (ATKINSON, 2006); é uma tarefa difícil e um caminho cheio de perigos (HREBINIAK, 2008); e, falha em vários níveis da organização (MARTIN, 2010).
Neste contexto, apesar dos estudos ao longo do tempo sobre o tema, à lacuna entre formulação e implementação da estratégia permanece, uma vez que grande parte das estratégias não são implementadas, informação evidenciada nos baixos índices de implementação registrados em relatos de pesquisas apresentados na Figura 1.

\begin{tabular}{|c|c|c|}
\hline Ano & Autor & Índices de implementação da Estratégia \\
\hline 1994 & Mintzberg & Mais da metade das estratégias formuladas não são implementadas. \\
\hline 2001 & Kaplan e Norton & Somente $10 \%$ das estratégias formuladas chegam a ser implementadas com êxito. \\
\hline 2004 & Raps & A taxa de sucesso na implementação da estratégia é apenas de 10\% a 30\%. \\
\hline 2005 & Hrebiniak & Frequentemente as estratégias não são implementadas com sucesso. \\
\hline 2006 & Kenny & Dados da revista Fortune revelam que menos de $10 \%$ das estratégias são implementadas de forma eficaz. \\
\hline 2007 & Yukl e Lepsinger & $\begin{array}{l}\text { Pesquisa da OnPoint Consulting revela que } 49 \% \text { dos entrevistados (mais de quatrocentos líderes de nível } \\
\text { gerencial) afirmam que suas organizações são ineficientes em execução e } 64 \% \text { não acreditam na melho- } \\
\text { ria deste quadro. }\end{array}$ \\
\hline 2008 & Kaplan e Norton & $\begin{array}{l}\text { Pesquisas indicam que } 60 \% \text { a } 80 \% \text { das empresas não alcançam seus objetivos estratégicos e } 73 \% \text { dos } \\
\text { executivos afirmam que suas empresas têm desempenho médio ou inferior na execução da estratégia. }\end{array}$ \\
\hline 2008 & Li, Guohui e Eppler & $\begin{array}{l}\text { 83\% das companhias pesquisadas falham na implementação de suas estratégias, de acordo com "White } \\
\text { Paper of Strategy Implementation of Chinese Corporations in 2006". }\end{array}$ \\
\hline 2009 & Jooste e Fourie & $\begin{array}{l}\text { Pesquisa realizada com líderes de } 200 \text { companhias da África do Sul revela que: } \\
55 \% \text { dos entrevistados concordam que sua organização é melhor em formulação da estratégia do que } \\
\text { implementação. } \\
51,4 \% \text { dos especialistas concordam que existem um gap entre a formulação da estratégia e sua efetiva } \\
\text { implementação. }\end{array}$ \\
\hline 2009 & Lacerda & $\begin{array}{l}\text { Pesquisa realizada em uma Universidade privada confessional registra que apenas } 20 \% \text { das intenções } \\
\text { estratégicas (objetivos estratégicos), possuem elementos significativos de sua implementação. } \\
\text { E 39\% das intenções estratégicas possuem um nível significativamente baixo de implementação. }\end{array}$ \\
\hline 2010 & Lacerda e Caulliraux & $\begin{array}{l}\text { Pesquisa realizada através de um estudo de caso em uma IES mostra que 39\% dos objetivos estratégicos } \\
\text { não possuem evidências de implementação. }\end{array}$ \\
\hline 2011 & Dandira & 73\% dos gerentes acreditam que a implementação é mais difícil que a formulação da estratégia. \\
\hline 2013 & Rose e Cray & $\begin{array}{l}\text { Survey realizado com } 153 \text { gerentes seniores e executivos ( } 62 \% \text { de retorno) sobre o processo de imple- } \\
\text { mentação da estratégia teve o seguinte resultado: } 33,3 \% \text { dos entrevistados 'discordam' quando pergun- } \\
\text { tado se o processo de implementação tinha ocorrido exatamente como planejado. Quando a resposta é } \\
\text { 'discordo em parte' o percentual sobe para 48,4\%. }\end{array}$ \\
\hline
\end{tabular}

Figura 1 Índices de implementação da estratégia

Fonte: Elaborado pelos autores.

Assim, levando-se em consideração a complexidade do processo de formulação e implementação da estratégia, o qual leva a deficiência da implementação pelas organizações, estudos abaixo relacionados apre- sentam os principais obstáculos para implementação eficaz da estratégia, mostrados de forma resumida na Figura 2. 


\begin{tabular}{|c|c|}
\hline Obstáculos para implementação eficaz da estratégia & Autores (ano) \\
\hline Falta de relacionamento entre áreas organizacionais & Noble (1999a) \\
\hline Falta de um modelo claro, dominante e abrangente de implementação & $\begin{array}{l}\text { Noble (1999b); Okumus (2003); Hrebiniak (2006) } \\
\text { Kaplan e Norton (2008) }\end{array}$ \\
\hline Falta de clareza e conflito de prioridades & \multirow{5}{*}{ Beer e Eisenstat (2000) } \\
\hline Gerência ineficaz & \\
\hline Comunicação vertical 'pobre' & \\
\hline Fraca coordenação entre as funções e negócios & \\
\hline Inadequada habilidade de liderança & \\
\hline Falta de envolvimento dos responsáveis pela execução no processo de planejamento & \multirow{4}{*}{ Hrebiniak (2008) } \\
\hline Desafio da comunicação top-down & \\
\hline Gerentes acreditam que a implementação é responsabilidade dos 'executores' & \\
\hline Incapacidade de gerenciar mudanças & \\
\hline Sincronizar o pensamento estratégico com foco no curto prazo & \multirow{4}{*}{ Getz et al. (2009) } \\
\hline Diferenciar as estratégias mais importantes a fazer & \\
\hline Fazer distinção entre o estratégico e o tático & \\
\hline Compreender que a estratégia pode ser tanto determinista como emergente & \\
\hline Falta de entendimento da estratégia pela força de trabalho & \multirow{2}{*}{ Jooste e Fourie (2009) } \\
\hline Falta de comunicação da estratégia para força de trabalho & \\
\hline
\end{tabular}

Figura 2 Obstáculos para implementação eficaz da estratégia

Fonte: Elaborado pelos autores.

Adicionalmente, Noble (1999b) relata que o estilo de liderança pode comprometer a implementação da estratégia afetando o alcance dos resultados organizacionais; Beer e Eisenstat (2000; 2004) destacam a importância de uma conversa honesta entre líder e demais níveis hierárquicos a respeito da estratégia a fim de garantir sua implementação. Raps (2004) afirma que o sucesso na implementação tem como pré-requisito o envolvimento dos líderes na estratégia. Beatty e Quinn (2007) enfatizam que através do diálogo os líderes são capazes de minimizar o gap existente entre formulação e implementação da estratégia.

Em síntese, vários estudos demonstram a complexidade do processo de implementação da estratégia (NOBLE, 1999b; OKUMUS, 2003), uma vez que o sucesso da implementação ou execução da estratégia exige mais tempo e pessoas envolvidas do que a formulação (HREBINIAK, 2008); demanda mais energia do que a formulação (RAPS, 2004); depende do processo de formulação que é usado (HAMBRICK; CANELLA, 1989); frequentemente é mais difícil do que a formulação, uma vez que a implementação pode levar anos (ANDREWS; BOYNE; LAW; WALKER, 2011) e não há um framework dominante (OKUMUS, 2003) ao contrário do processo de formulação, onde modelos e ferramentas como, matriz SWOT, as cinco forças de Porter, entre outras são amplamente reconhecidas e utilizadas.

Diante do exposto, a fim de auxiliar na eficácia da implementação da estratégia, pesquisas buscam consolidar um modelo para implementação da estratégia (BEER e EISENSTAT, 2000; FREEDMAN, 2003; HAMBRICK; CANELLA, 1989; HREBINIAK, 2006; KAPLAN; NORTON, 2008; LABOVITZ; ROSANSKY, 1997; NOBLE, 1999a; OKUMUS, 2003).

Prieto et al. (2009) identificaram e analisaram quatro modelos de implementação da estratégia que servem como referência para o processo de alinhamento estratégico interno (estrutura, sistemas e liderança), o qual deve levar a implementação bem sucedida da estratégia, são eles: Modelo Hambrick e Cannella (1989); Modelo Organizational Fitness Pro- 
filing [OFP] (proposto por Beer e Eisenstat - 2000); Modelo Labovitz e Rosansky (1997); Modelo Balanced Scorecard (proposto por Kaplan e Norton -1990).

Ressalta-se que o conceito de alinhamento estratégico faz parte do processo de gestão estratégica, sendo um requisito presente tanto no processo de formulação quanto implementação da estratégia (VENKATRAMAN; CAMILLUS, 1984).

Diante dos modelos de implementação e alinhamento citados por este artigo, adotou-se como critério apresentar de forma sucinta e comparativa os modelos que de alguma maneira utilizam alinhamento estratégico como fator relevante para o alcance dos objetivos estratégicos e consideram a interdependência entre formulação e implementação da estratégia, ou seja, acreditam que há uma relação de dependência entre formulação e implementação da estratégia. Assim, os três modelos de implementação e alinhamento apresentados são: modelos de Hambrick e Canella (1989), o Balanced Scorecard de Kaplan e Norton $(1997 ; 2008)$ e o modelo de implementação de Hrebiniak (2006).

\section{Modelo de Hambrick e Cannella}

O modelo é caracterizado pela definição de três etapas a serem conduzidas pelo próprio estrategista, são elas: 1) 'preparação do terreno' para formulação da nova estratégia e inclui amplas entradas para formulação e cuidados com os obstáculos para implementação; 2) 'influências relevantes na implementação' segundo cinco aspectos: comprometimento de recursos, políticas e programas das subunidades, estrutura, recompensas, e pessoas; 3 ) 'convencimento da estratégia' a qual deve envolver todos os níveis da organização, de baixo para cima, de cima para baixo, para fora e interdepartamental, a fim de manter um suporte necessário para a implementação eficaz da estratégia, levando em consideração as resistências que surgem nesse processo (HAMBRICK; CANELLA, 1989).

Verifica-se assim a importância atribuída ao estrategista no modelo de Hambrick e Canella (1989), o qual deve dar suporte desde a formulação até a implementação da estratégia em meio às resistências que podem surgir no ambiente organizacional por motivos diversos.

\section{Modelo de Kaplan e Norton}

O modelo do Balanced Scorecard considera a estratégia formulada, a qual será desdobrada em scorecards, integrando todas as medidas de desempenho (KAPLAN; NORTON, 1997; 2008). Para Kaplan e Norton (2006, p. 293), "a ideia principal é que a estratégia é o centro do modelo de gestão. A partir da clara definição da estratégia, todos os componentes do processo de gestão podem ser desenvolvidos para promover o alinhamento". Assim, as etapas do modelo propostas por Kaplan e Norton (2008) fazem o link da formulação com a execução da estratégia e apoiam-se em dois eixos principais enquanto sistema de alinhamento estratégico, o eixo da comunicação (presente na etapa do planejamento da estratégia) e do controle da estratégia (verificado na etapa de monitoramento e aprendizado) (PRIETO; CARVALHO; FISCHMANN, 2009).

O modelo de Kaplan e Norton procura traduzir a visão e a estratégia da organização em objetivos, que são desdobrados em medidas, metas e iniciativas estratégicas sob a ótica de quatro perspectivas: financeira, clientes, processos internos e de aprendizado e crescimento (KAPLAN; NORTON, 1997; 2006; 2008).

\section{Modelo de Hrebiniak}

O modelo de execução da estratégia apresentado por Hrebiniak (2006) é focado na formulação de uma estratégia sólida, havendo uma grande interdependência entre formulação e implementação, apesar de serem etapas distintas. Isso justifica a inclusão da formulação da estratégia no seu modelo. Em segundo lugar o modelo mostra um fluxo lógico de decisões ou ações da execução através das setas, mostrando, por exemplo, que a estratégia corporativa está no início do modelo por ser primordial e os incentivos e controle, por último, pois só devem ser definidos depois que todas as decisões forem tomadas. O fluxo também sugere a participação e comunicação tanto vertical quanto horizontal entre as unidades operacionais. Em terceiro lugar, apesar de não estar evidente no modelo, o autor afirma que o item de 'controle' é realizado através dos feedbacks e alterações.

Por fim, Hrebiniak (2006) enfatiza que a execução é um processo dinâmico e adaptativo, levando a 
aprendizagem organizacional através dos feedbacks sobre o desempenho. Verifica-se também que o alinhamento está presente na integração da estrutura corporativa e na integração da estrutura empresarial.
A Figura 3 apresenta de forma comparativa uma síntese das principais características dos modelos selecionados.

\begin{tabular}{|c|c|c|c|}
\hline \multirow[b]{2}{*}{ Características } & \multicolumn{3}{|c|}{ Modelos } \\
\hline & $\begin{array}{l}\text { Hambrick e } \\
\text { Canella (1989) }\end{array}$ & $\begin{array}{c}\text { Kaplan e Norton } \\
(97 / 2008)\end{array}$ & Hrebiniak (2006) \\
\hline Formulação e implementação como parte do mesmo processo & $\boldsymbol{*}$ & & \\
\hline Formulação e implementação como etapas distintas & & $\boldsymbol{*}$ & $\boldsymbol{*}$ \\
\hline Interdependência entre formulação e implementação & $\boldsymbol{*}$ & $*$ & $\boldsymbol{*}$ \\
\hline Importância dada às análises do ambiente interno e externo & $\boldsymbol{*}$ & $\boldsymbol{*}$ & \\
\hline Envolv. de todos os níveis e áreas da organização no processo estratégico & $\boldsymbol{*}$ & $*$ & * \\
\hline Alinhamento estratégico como requisito para implementação. & $\boldsymbol{*}$ & $\ddot{*}$ & $\boldsymbol{*}$ \\
\hline
\end{tabular}

Figura 3 Síntese dos modelos apresentados

Fonte: Elaborado pelos autores.

Verifica-se assim que enquanto o modelo de Hambrick e Canella (1989) consideram que a formulação e implementação fazem parte do mesmo processo, o modelo de Kaplan e Norton (1997; 2008) e Hrebiniak (2006) apresentam como etapas distintas, apesar de acreditarem na interdependência entre a formulação e implementação. Uma das semelhanças entre os modelos de Hambrick e Canella (1989) e Kaplan e Norton $(1997 ; 2008)$ é a importância dada às análises de ambientes interno e externo. Verificou-se, também, que os três modelos em determinados momentos, envolvem todos os níveis e áreas da organização buscando maximizar a eficácia da implementação da estratégia. As semelhanças encontradas nos modelos podem ser justificadas pelo fato de todos utilizarem o alinhamento estratégico como requisito para implementação.

Outro tema central que contribui para a gestão estratégica organizacional são os estudos de futuro. Segundo Cagnin (2014, p. 55) "a partir do ano 2000, o escopo e o foco dos estudos de futuro são ampliados de forma a abranger uma diversidade de temas. Métodos começam a ser usados com mais critério e de acordo com o contexto". Para Cagnin (2014) os estudos de futuro no Brasil podem ser incorporados explicitamente nos processos de tomada de decisão e planejamento.
Neste campo, estão inseridos os exercícios de FTA - Análise das Tecnologias Orientadas para o Futuro (Future Oriented Technology Analysis), os quais apresentam diversas formas de analisar o futuro e contribuem para reduzir as incertezas do ambiente organizacional, onde enquadram-se várias abordagens, métodos, ferramentas e técnicas, como por exemplo, Forecast(ing), Foresight(ing), Roadmapp (ing), Technology Intelligence, Assessment, Scenarios, Delphi, Trend-Impact Analysis; Cross-Impact Analysis, Morphological Analysis, entre outros (PORTER et al., 2004).

Eerola e Miles (2011) e Loveridge e Saritas (2012) corroboram Porter et al. (2004) quando afirmam que os subcampos do FTA incluem: foresight, forecasting, technology assessment, futures research entre outros. Eerola e Miles (2011) veem os exercícios de FTA como uma tentativa de coletar conhecimentos sobre possíveis futuros, sua plausibilidade e limites, sua coerência com o parecer dos experts e suas implicações.

FTA é considerado, assim, um termo 'guarda-chuva’ e genérico para designar um amplo conjunto de atividades, métodos e técnicas a fim de identificar futuros alternativos para melhorar nossa capacidade de viver em um mundo imprevisível. Segundo Loveridge e Saritas (2012), FTA ajuda a desenvolver hipóteses de como situações presentes podem evoluir 
no futuro, utilizando com frequência os cenários para essa atividade, tema apresentado na próxima seção.

\subsection{Origens e conceitos dos cenários}

Pesquisas sobre o futuro têm suas raízes heterogêneas, incluindo pesquisas operacionais, planejamento de cenários e gestão estratégica. O conceito de planejamento de cenário surgiu pela primeira vez após a Segunda Guerra Mundial, como um método de planejamento militar (BRADFIELD; WRIGHTB; BURTA; CAIRNSB; HEIJDEN, 2005; MIETZNER; REGER, 2004). Na década de 1960, a palavra 'cenário' foi introduzida por Herman Kahn como ferramenta de previsão (GODET, 1994; GODET; ROUBELAT, 1996; MIETZNER; REGER, 2004).

No início da década de 70, a partir do trabalho de Pierre Wack, os cenários atingem uma nova dimensão, explicada pelo efeito traumático da crise de petróleo em 1973, em que somente a Shell estava preparada para mudança (HEIJDEN, 2009; MIETZNER; REGER, 2004; RATCLIFFE, 2000). A partir da década de 70, outras organizações de grande porte, como, por exemplo, Global Business Network [GBN], Motorola, Banco Nacional de Desenvolvimento Econômico e Social [BNDES], Eletrobrás, Petrobras, Eletronorte, dentre outras, começaram a utilizar análise de cenários como instrumento da gestão estratégica (HEIJDEN, 2009).

A definição mais abrangente e acadêmica encontrada na literatura segundo Marcial e Grumbach (2008, p.47) é a de Godet, Monti, Meunier e Roubelat (2000), o qual define Cenário como "um conjunto formado pela descrição de uma situação futura e do encaminhamento dos acontecimentos que permitem passar da situação de origem a essa situação futura".

Segundo Godet (1994); Godet e Roubelat (1996); Godet et al. (2000), cenários podem ser identificados a partir de duas categorias principais: exploratório construídos a partir das tendências do passado e do presente levando a um futuro provável e o normativo ou de antecipação os quais são construídos a partir de diferentes visões do futuro, podendo ser desejados ou temidos. Já Borjeson, Hojer, Dreborg, Ekvall e Finnveden (2006) classificam em três principais categorias e seis tipos, a saber: preditivo (do tipo: forecasts e what-if); exploratório (do tipo: externo e estratégico); e normativo (do tipo: preservação e transformação).

Porter (1992, p. 413); Godet (1994, p.29); Godet et al. (2000, p.31); Ratcliffe (2000, p.5); Ogilvy e Schwartz (2004); Mietzner e Reger (2004, p. 48-49); Heijden (2009, p. 308); Loveridge (2009, p. 150) afirmam que os cenários não são previsões (forecasts) nem uma realidade futura e sim a representação de algo que poderia acontecer a fim de melhorar a decisão sobre um resultado futuro possível (foresight), visando iluminar a ação presente.

A seguir, descrevem-se, de forma sucinta, as principais abordagens/escolas de cenários e os principais Métodos de Cenários.

\subsubsection{Principais escolas e métodos de cenários}

Ressalta-se que a quantidade de técnicas, modelos, metodologias e abordagens de cenários apresentados na literatura tem gerado o chamado 'caos metodológico' (AMER; DAIM; JETTER, 2013; BRADFILED et al. 2005; VARUM; MELO, 2010), levando a uma variedade de definições, nomenclaturas, abordagens e classificações acerca do tema.

Em seus estudos, Bradfield et al. (2005) e Amer et al. (2013) afirmam que há três abordagens/escolas dominantes, são elas: Lógica Intuitiva (Intuitive Logics); Tendência Modificada Probabilística (Probabilistic Modified Trend); e Prospectiva (La Prospective).

A escola Lógica Intuitiva (Intuitive Logics) foi proposta por Herman Kahn na Rand Corporation na década de 1960 e usada por Pierre Wack (1985) na Royal Dutch Shell, sendo referida, muitas vezes, por 'abordagem Shell' para cenários. Essa abordagem também é descrita como 'escola anglo-americana' de planejamento de cenários, sendo dominante no desenvolvimento de cenários nos Estados Unidos.

A escola Probabilística adota a abordagem Tendência Modificada Probabilística [PMT] cujas bases são os trabalhos de Helmer e Gordon na Rand Corporation na década de 50, nos Estados Unidos. Essa abordagem incorpora duas metodologias diferentes, chamadas de: Análise do Impacto de Tendência [TIA] e Análise dos Impactos Cruzados [CIA]. E, a escola Francesa, cuja abordagem é Prospectiva [ La Prospective] foi desenvolvida a partir de 1960 pelo trabalho pioneiro dos franceses Berger, Masse e Jouvenel na 
década de 50, sendo largamente ampliada com os trabalhos de Godet, a partir de 1970 (AMER et al. 2013; BRADFIELD et al., 2005).

Amer et al. (2013) expõem que a principal diferença entre as escolas é a abordagem metodológica.
Enquanto a abordagem 'PMT' é de natureza quantitativa, a 'lógica intuitiva' é qualitativa e a abordagem 'La Prospectiva' faz a combinação da abordagem quantitativa e qualitativa.

\begin{tabular}{|c|c|c|c|}
\hline Ano & Autor & Método & Macro etapas para elaboração dos cenários \\
\hline 1975 & $\begin{array}{l}\text { Mike Coles e } \\
\text { Tom Leney }\end{array}$ & CEDEFOP & $\begin{array}{l}\text { 1. Definir o problema; criar a equipe encarregada dos cenários; } 2 \text {. Detectar as principais for- } \\
\text { ças de mudança no entorno; } 3 \text {. Reunir dados sobre tendências relevantes; } 4 \text {. Classificar as } \\
\text { tendências em três categorias; } 5 \text {. Decidir sobre os principais fatores de resultado incerto; } \\
6 \text {. Dispor dos elementos básicos dos cenários em forma de matriz; } 7 \text {. Redigir os cenários } \\
\text { provisórios; } 8 \text {. Comprovar a plausibilidade e a coerência interna dos cenários; } 9 \text {. Modificar, } \\
\text { aperfeiçoar e apresentar os cenários; } 10 \text {. Manter os cenários em constante revisão. }\end{array}$ \\
\hline 1979 & General Eletric & $\begin{array}{l}\text { Método General } \\
\text { Electric [GE] }\end{array}$ & $\begin{array}{l}\text { 1. Preparação das bases; } 2 \text {. Escolha e planejamento dos indicadores críticos de prospec- } \\
\text { ção; 3. Trajetória do comportamento passado de cada indicador escolhido; } 4 \text {. Verificação } \\
\text { dos eventos futuros potenciais e sua consistência; } 5 \text {. Prospecção de cada indicador esco- } \\
\text { Ihido (análise de impactos cruzados); } 6 \text {. Estruturação e modelagem final do(s) Cenário(s) } \\
\text { prospectados; } 7 \text {. Elaboração e envio dos guias aos setores competentes para execução. }\end{array}$ \\
\hline $\begin{array}{l}1985 \\
1992\end{array}$ & Michael Porter & $\begin{array}{l}\text { Método de Cená- } \\
\text { rio Industrial }\end{array}$ & $\begin{array}{l}\text { 1. Identificação das principais incertezas na estrutura industrial; } 2 \text {. Determinação dos } \\
\text { respectivos fatores causais; } 3 \text {. Escolha das variáveis de cenários; } 4 \text {. Definição de confi- } \\
\text { guração futura para as variáveis de cenários; } 5 \text {. Construção dos cenários; } 6 \text {. Análise dos } \\
\text { cenários; } 7 \text {. Análise da estrutura industrial em cada Cenário; } 8 \text {. Introdução do comporta- } \\
\text { mento da concorrência nos Cenário; } 9 \text {. Escolha das estratégias competitivas. }\end{array}$ \\
\hline $\begin{array}{l}1990 \\
1994 \\
1996 \\
2000\end{array}$ & Michel Godet & Método Godet & $\begin{array}{l}\text { 1. Delimitação do sistema e do ambiente; } 2 \text {. Análise estrutural do sistema e do ambien- } \\
\text { te; } 3 \text {. Análise atual e retrospectiva; } 4 \text {. Análise do 'jogo de atores'; } 5 \text {. Análise morfológica; } 6 \text {. } \\
\text { Elaboração dos cenários. }\end{array}$ \\
\hline 2004 & Peter Schwartz & $\begin{array}{l}\text { Global Business } \\
\text { Network [GBN] }\end{array}$ & $\begin{array}{l}\text { 1. Identificação da questão principal; } 2 \text {. Identificação das principais forças do ambiente } \\
\text { local (fatores- chave); } 3 \text {. Identificação das forças motrizes (macroambiente); } 4 \text {. Ranking } \\
\text { por importância das incertezas críticas; } 5 \text {. Seleção das lógicas dos cenários; } 6 \text {. Descrição } \\
\text { dos cenários; } 7 \text {. Análise das implicações e opções; } 8 \text {. Seleção dos principais indicadores } \\
\text { e sinalizadores. }\end{array}$ \\
\hline $\begin{array}{l}1996 \\
2008\end{array}$ & Raul Grumbach & $\begin{array}{l}\text { Método Raul } \\
\text { Grumbach }\end{array}$ & $\begin{array}{l}\text { 1. Identificação do sistema; 2. Diagnóstico estratégico; 3. Visão estratégica; 4. Consolida- } \\
\text { ção do planejamento. }\end{array}$ \\
\hline 2009 & $\begin{array}{l}\text { Kees Van der } \\
\text { Heijden }\end{array}$ & $\begin{array}{l}\text { Método Kees } \\
\text { Van der Heijden }\end{array}$ & $\begin{array}{l}\text { 1. Agenda de cenários; 2. Dimensões-chave; 3. Estado final dos cenários; } \\
\text { 4. Cenários prototípicos; } 5 \text {. Comparação (business-as-usual); 6. Questões de pesquisa; } 7 . \\
\text { Análise de sistemas; 8. Compreensão sistêmica. }\end{array}$ \\
\hline 2009 & Denis Loveridge & $\begin{array}{l}\text { Método Denis } \\
\text { Loveridge }\end{array}$ & $\begin{array}{l}\text { 1. Descrição preliminar da situação, seus limites e horizonte de tempo; } \\
\text { 2. Estabelecer um amplo programa de aprendizagem; } 3 \text {. Tornar explícitos os pressupos- } \\
\text { tos para descrever os cenários; } 4 \text {. Construir um conjunto de eventos alternativos e ten- } \\
\text { dências que serão os 'esqueletos' para os cenários; } 5 \text {. Descrever os cenários; } 6 \text {. Analisar os } \\
\text { cenários; } 7 \text {. A partir da análise, emergem políticas alternativas para melhoria; } 8 \text {. A partir } \\
\text { dos instrumentos de política, emergem estratégias adaptáveis; } 9 \text {. Avaliar as estratégias. }\end{array}$ \\
\hline
\end{tabular}

Figura 4 Principais Métodos de elaboração de cenários

Fonte: Elaborado pelos autores.

Destaca-se, que apenas a escola 'lógica intuitiva' tem seu processo de orientação metodológica essencialmente subjetiva e qualitativa, ou seja, não utiliza nenhum algoritmo matemático e os Métodos de Cenários propostos por Schwartz e Van der Heijden pertencem a essa abordagem (PILLKAHN, 2008).
Adicionalmente, é possível enquadrar os Métodos de Cenários propostos por Mike Coles e Tom Leney e Denis Loveridge dentro da abordagem 'lógica intuitiva'. Já as abordagens 'La Prospectiva' e 'PMT' que utilizam algoritmo matemático, podem ser relacionados aos Métodos de Cenários que apresentam 
algum tipo de modelo matemático em sua etapa de elaboração, conforme apresentados na Figura 4, em ordem temporal, uma síntese dos principais Métodos de Cenários.

Diante dos diversos métodos encontrados, Godet et al. (2000) afirmam que os diferentes passos/ etapas não diferem muito. Em todos os métodos encontrados, pode-se dizer que existem basicamente três etapas/passos essenciais, são eles: identificar as variáveis-chave; colocar as questões-chave para o futuro; e, reduzir a incerteza sobre as questões-chave definindo os cenários mais prováveis.

\section{METODOLOGIA DA PESQUISA}

O presente estudo classifica-se como bibliométrico ao objetivar conhecer o estado da arte, compreender e descrever as análises relacionadas aos temas 'cenários', 'formulação e implementação da estratégia' e 'alinhamento estratégico'.

A partir do objetivo desta pesquisa, escolheram-se as palavras-chave para a busca de referências conforme Figura 5.

\begin{tabular}{c|c}
\hline $\mathbf{n o}$ & Palavras-chave \\
\hline 1 & Scenarios \\
\hline 2 & scenarios - strategy formulation \\
\hline 3 & scenarios - strategic formulation \\
\hline 4 & scenarios - strategy implementation \\
\hline 5 & scenarios - strategic implementation \\
\hline 6 & scenarios - strategy alignment \\
\hline 7 & scenarios - strategic alignment \\
\hline
\end{tabular}

Figura 5 Palavras-chave da pesquisa

Fonte: Elaborado pelos autores.

Definidas as palavras-chave, foram realizadas buscas nas principais bases de dados às quais contemplavam a área de conhecimento de administração: Proquest; EBSCO, Periódico CAPES e SPELL. Também foram realizadas buscas exploratórias nos principais Journals com publicações sobre estudos futuros 'futures studies', os quais eram vocacionados para FTA e contemplavam o tema 'cenários', conforme abaixo:
- Journals: Technological Forecasting and Social Change [TFSC]; Technology Analysis and Strategic Management [TASM]; Futures e Foresight.

Por fim, foram realizadas buscas nas bases de dados de eventos nacionais da área de administração e produção e um evento internacional especifico sobre FTA que contemplam o tema desta pesquisa, conforme abaixo:

- Eventos Nacionais: ENANPAD; 3ES; SEMEAD; SIMPOI e ENEGEP.

- Evento Internacional: International Conference on Future-Oriented Technology Analysis (FTA).

Após o levantamento do estado da arte, realizaram-se duas etapas para seleção dos artigos considerados neste estudo:

- 1a etapa: foi realizada uma análise do título e resumo com o tema 'cenários' e 'cenários' relacionado à 'formulação e implementação da estratégia' e 'alinhamento estratégico', sendo selecionados 117 artigos.

- 2a etapa: foram analisados o conteúdo dos 117 artigos a fim de identificar quais destes abordavam a contribuição e relevância dos cenários para o alinhamento entre a formulação e implementação da estratégia, sendo identificados 24 artigos.

Assim, apresenta-se no próximo tópico (Figura 6) uma análise dos 24 artigos identificados.

É importante destacar ainda que, foram realizadas também buscas exploratórias, em todas as bases supracitadas, sobre os temas 'formulação e implementação da estratégia' e 'alinhamento estratégico’ e buscas exploratórias de teses e dissertações no portal de periódicos da CAPES, sendo utilizados na elaboração do referencial teórico.

\section{RESULTADOS}

A partir do levantamento teórico acerca do tema, foram identificados estudos apresentados na Figura 6 que citam a contribuição e relevância dos Métodos de 
Cenários para a gestão estratégica, o qual se mostra apropriado para lidar com a incerteza, minimizar as ameaças relacionadas com o futuro, melhorar a tomada de decisão e maximizar o alinhamento entre a formulação e implementação da estratégia.

A Figura 6 descreve os achados a partir do ano de publicação do estudo; identificação dos autores; denominação do tipo de estudo analisado (teórico ou empírico); uma síntese da contribuição do Método de Cenário para a gestão estratégica e a principal contribuição em termos de formulação e/ou implementação da estratégia dos estudados identificados.

\begin{tabular}{|c|c|c|c|c|}
\hline Ano & Autor & $\begin{array}{l}\text { Tipo de } \\
\text { Estudo }\end{array}$ & Contribuição dos cenários para Gestão Estratégica & $\begin{array}{c}\text { Principal } \\
\text { contribuição }\end{array}$ \\
\hline 1992 & Porter & Teórico & $\begin{array}{l}\text { A partir do momento que a empresa sente necessidade de uma aborda- } \\
\text { gem mais explícita da incerteza, a fim de compreender as implicações } \\
\text { estratégicas de um modo mais completo, ela passa a utilizar os cenários. } \\
\text { Caso não se utilize os cenários na formulação estratégica, todo seu esforço } \\
\text { será inútil. }\end{array}$ & $\begin{array}{l}\text { Formulação da } \\
\text { estratégia }\end{array}$ \\
\hline 2000 & Godet; Godet et al. & Teórico & $\begin{array}{l}\text { A construção de cenários podem iluminar as escolhas estratégicas, reduzir } \\
\text { as incertezas e assegurar a perenidade do negócio, principalmente em } \\
\text { ambientes de múltiplas incertezas. } \\
\text { Desde os anos } 80 \text { os autores estudam a sinergia entre prospectiva e estra- } \\
\text { tégia, o que deu origem a uma metodologia integrada do planejamento } \\
\text { estratégico com base em cenários. Propor ações estratégicas alinhadas } \\
\text { às competências da empresa em função dos cenários é o objetivo da } \\
\text { metodologia integrada de Godet et al. (2000). }\end{array}$ & $\begin{array}{l}\text { Formulação da } \\
\text { estratégia }\end{array}$ \\
\hline 2000 & Johnston & Teórico & $\begin{array}{l}\text { Dentre os principais métodos prospectivos, o Cenário é a abordagem } \\
\text { mais adequada à formulação de estratégias e permite melhores decisões } \\
\text { estratégicas. }\end{array}$ & $\begin{array}{l}\text { Formulação da } \\
\text { estratégia }\end{array}$ \\
\hline 2000 & Ratcliffe & Teórico & $\begin{array}{l}\text { Cenários tem se mostrado como um instrumento poderoso e eficaz no } \\
\text { planejamento estratégico. Assim, o autor vê a prática de cenários como } \\
\text { suporte para a gestão estratégica organizacional. }\end{array}$ & $\begin{array}{l}\text { Formulação e } \\
\text { implementação } \\
\text { da estratégia }\end{array}$ \\
\hline 2001 & $\begin{array}{l}\text { Chermack, Ly- } \\
\text { nham e Ruona }\end{array}$ & Teórico & $\begin{array}{l}\text { O Método de Cenário contribui de forma significativa com o planejamen- } \\
\text { to estratégico tradicional, visto como um instrumento poderoso para } \\
\text { gestão estratégica. }\end{array}$ & $\begin{array}{l}\text { Formulação e } \\
\text { implementação } \\
\text { da estratégia }\end{array}$ \\
\hline 2002 & Berkhout e Hertin & Teórico & $\begin{array}{l}\text { Cenários contemporâneos tendem a basear-se no princípio de transpa- } \\
\text { rência (relação explícita entre os dirigentes) e diversidade (ir além de uma } \\
\text { única estimativa, encorajar os dirigentes a explorar diferentes lógicas e } \\
\text { caminhos consistentes a fim de responder as perguntas do futuro). Assim, } \\
\text { o planejamento por cenários pode agregar valor a definição da estratégia. }\end{array}$ & $\begin{array}{l}\text { Formulação da } \\
\text { estratégia }\end{array}$ \\
\hline $\begin{array}{l}2004 \\
2006\end{array}$ & $\begin{array}{l}\text { Rocha; } \\
\text { Rocha e Oliveira }\end{array}$ & Teórico & $\begin{array}{l}\text { Cenários mostram-se como uma ferramenta que pode auxiliar na formu- } \\
\text { lação da estratégia da organização, contribuindo assim com o posiciona- } \\
\text { mento estratégico. }\end{array}$ & $\begin{array}{l}\text { Formulação da } \\
\text { estratégia }\end{array}$ \\
\hline 2004 & Fink et al. & Teórico & $\begin{array}{l}\text { Os autores destacam que um dos princípios da gestão de cenários é } \\
\text { justamente o 'pensamento estratégico' o qual busca identificar os pré- } \\
\text {-requisitos do sucesso futuro como uma base para o desenvolvimento e } \\
\text { implementação das estratégias. Para os autores, o uso de cenários deve } \\
\text { apoiar a tomada de decisão no curto prazo no processo de planejamento } \\
\text { estratégico, dando suporte ao desenvolvimento da estratégia. }\end{array}$ & $\begin{array}{l}\text { Formulação e } \\
\text { implementação } \\
\text { da estratégia }\end{array}$ \\
\hline
\end{tabular}

Figura 6 Contribuição dos cenários para gestão estratégica

Fonte: Elaborado pelos autores. 


\begin{tabular}{|c|c|c|c|c|}
\hline Ano & Autor & $\begin{array}{l}\text { Tipo de } \\
\text { Estudo }\end{array}$ & Contribuição dos cenários para Gestão Estratégica & $\begin{array}{c}\text { Principal } \\
\text { contribuição }\end{array}$ \\
\hline 2004 & $\begin{array}{l}\text { Richards, O'Shea e } \\
\text { Connolly }\end{array}$ & Empírico & $\begin{array}{l}\text { Os autores realizaram um estudo de caso na Universidade de Glamorgan } \\
\text { (UK), a qual introduziu o planejamento de cenários na sua metodologia } \\
\text { tradicional. A metodologia se mostrou efetiva por quatro principais razões: } \\
\text { maior envolvimento das pessoas; trouxe maior desafio de tornar a estraté- } \\
\text { gia explícita; modelo aberto aos desafios das forças internas e externas e } \\
\text { desafia os 'modelos mentais'. Por fim, os autores ressaltam sua importância } \\
\text { para formulação da estratégia. }\end{array}$ & $\begin{array}{l}\text { Formulação da } \\
\text { estratégia }\end{array}$ \\
\hline 2005 & $\begin{array}{l}\text { Fink, Marr, Siebe e } \\
\text { Kuhle }\end{array}$ & Teórico & $\begin{array}{l}\text { O planejamento estratégico baseado em cenários demonstra como as } \\
\text { organizações podem criar cenários estratégicos internos (RBV) visando } \\
\text { complementar os cenários externos (baseado no mercado) a fim de me- } \\
\text { lhorar sua visão estratégica e maximizar o controle estratégico. }\end{array}$ & $\begin{array}{l}\text { Formulação da } \\
\text { estratégia }\end{array}$ \\
\hline 2005 & Moritz e Pereira & Teórico & $\begin{array}{l}\text { O artigo foca a técnica de cenários prospectivos, fazendo um relato histórico } \\
\text { da evolução dessa metodologia, apresentando os principais atores relacio- } \\
\text { nados com o assunto e suas respectivas contribuições para a evolução do } \\
\text { pensamento prospectivo. Para os autores, cenários desempenham papel } \\
\text { relevante na gestão estratégica das organizações, os quais podem contribuir } \\
\text { para maximizar a eficácia da formulação e implementação da estratégia. }\end{array}$ & $\begin{array}{l}\text { Formulação e } \\
\text { implementação } \\
\text { da estratégia }\end{array}$ \\
\hline 2006 & $\begin{array}{l}\text { Breternitz, Al- } \\
\text { meida, Ercolin e } \\
\text { Sacramento }\end{array}$ & Empírico & $\begin{array}{l}\text { Breternitz et al. (2006, p.15), a partir de um estudo de caso afirmam que } \\
\text { "há evidências de que os Métodos de Cenários se apresentam como um } \\
\text { dos mais evoluídos instrumentos para dar suporte ao desenvolvimento da } \\
\text { estratégia de uma dada organização". }\end{array}$ & $\begin{array}{l}\text { Formulação da } \\
\text { estratégia }\end{array}$ \\
\hline 2007 & Franco & Empírico & $\begin{array}{l}\text { Em sua tese, o autor desenvolve uma metodologia para identificação } \\
\text { de um Cenário normativo aceitável e exequível. A metodologia integra } \\
\text { conceitos de planejamento estratégico, cenários e interações estratégicas. } \\
\text { O autor conclui que a metodologia pode fornecer respostas consistentes } \\
\text { a problemas complexos e que o planejamento estratégico agregado a } \\
\text { uma correta visão dos futuros possíveis, consiste em uma ferramenta para } \\
\text { construção de um futuro melhor. }\end{array}$ & $\begin{array}{l}\text { Formulação e } \\
\text { implementação } \\
\text { da estratégia }\end{array}$ \\
\hline 2007 & $\begin{array}{l}\text { Costa, Fischmann, } \\
\text { Boaventura, Muniz } \\
\text { e Nery }\end{array}$ & Empírico & $\begin{array}{l}\text { O artigo apresenta os resultados de uma investigação sobre a adequação } \\
\text { e a utilização de cenários prospectivos em uma instituição pública do } \\
\text { setor de turismo em Natal, através de um estudo de caso. O estudo mostra } \\
\text { que apesar da pouca profundidade no conhecimento de cenários e no } \\
\text { seu processo de elaboração, a instituição apresenta-se receptiva ao méto- } \\
\text { do, reconhecendo sua utilidade para a gestão estratégica. }\end{array}$ & $\begin{array}{l}\text { Formulação e } \\
\text { implementação } \\
\text { da estratégia }\end{array}$ \\
\hline 2008 & Moritz et al. & Empírico & $\begin{array}{l}\text { Os autores apresentam a experiência de uma empresa de grande porte } \\
\text { que aplicou um Método de Cenário, em 1998, comparando os resultados } \\
10 \text { anos depois. Como resultado, o estudo destacou que os cenários de- } \\
\text { sempenham papel relevante na formulação e implementação estratégica } \\
\text { desta empresa, atribuindo o sucesso da situação atual, em grande parte, } \\
\text { aos cenários. Destacou-se também que os cenários podem contribuir na } \\
\text { aglutinação dos esforços organizacionais e que é possível relacionar a } \\
\text { metodologia tradicional de administração estratégica com a prospecção } \\
\text { de cenários. }\end{array}$ & $\begin{array}{l}\text { Formulação e } \\
\text { implementação } \\
\text { da estratégia }\end{array}$ \\
\hline 2008 & Pillkahn e Sasano & Empírico & $\begin{array}{l}\text { Sua metodologia considera o ambiente organizacional externo e interno, } \\
\text { facilitando a identificação de estratégias robustas. Os autores afirmam que } \\
\text { a metodologia é um instrumento poderoso para tomada de decisão e } \\
\text { planejamento estratégico. }\end{array}$ & $\begin{array}{l}\text { Formulação e } \\
\text { implementação } \\
\text { da estratégia }\end{array}$ \\
\hline 2010 & $\begin{array}{l}\text { Wright, Silva e } \\
\text { Spers }\end{array}$ & Empírico & $\begin{array}{l}\text { Os autores desenvolveram possíveis cenários para o Brasil em } 2020 \text { e iden- } \\
\text { tificaram o cenário mais provável através da aplicação do método Delphi. } \\
\text { O estudo utilizou à atribuição de probabilidades subjetivas (opinião dos } \\
\text { especialistas que determinado resultado poderá ocorrer) para identificar } \\
\text { o Cenário mais provável. A partir de seu trabalho, os autores corroboram } \\
\text { pesquisas anteriores ao constatar que os cenários ajudam na formulação } \\
\text { estratégica permitindo melhores decisões estratégicas. }\end{array}$ & $\begin{array}{l}\text { Formulação da } \\
\text { estratégia }\end{array}$ \\
\hline
\end{tabular}

Figura 6 Contribuição dos cenários para gestão estratégica Fonte: Elaborado pelos autores. 


\begin{tabular}{|c|c|c|c|c|}
\hline Ano & Autor & $\begin{array}{l}\text { Tipo de } \\
\text { Estudo }\end{array}$ & Contribuição dos cenários para Gestão Estratégica & $\begin{array}{l}\text { Principal } \\
\text { contribuição }\end{array}$ \\
\hline 2011 & Santos & Empírico & $\begin{array}{l}\text { Em sua tese, a autora desenvolveu um modelo integrador a partir de } \\
\text { um estudo de caso na Eletrobrás com objetivo de consolidar o processo } \\
\text { de formulação de estratégias múltiplas potencializada com o uso dos } \\
\text { cenários, constituindo um instrumento relevante para tomada de decisão } \\
\text { estratégica no ambiente de incertezas. }\end{array}$ & $\begin{array}{l}\text { Formulação da } \\
\text { estratégia }\end{array}$ \\
\hline 2011 & Gonçalves & Empírico & $\begin{array}{l}\text { Em sua dissertação, a autora propõe um processo de avaliação a partir das } \\
\text { áreas e variáveis relevantes para a análise ambiental e elaboração de ce- } \\
\text { nários, auxiliando os gestores na definição das estratégias organizacionais. } \\
\text { Assim, segundo a autora, a partir da análise de cenários pode-se prever o } \\
\text { futuro proporcionando base sólida para definir as questões estratégicas. }\end{array}$ & $\begin{array}{l}\text { Formulação da } \\
\text { estratégia }\end{array}$ \\
\hline 2011 & Sayers & Teórico & $\begin{array}{l}\text { Em seu artigo, a autora trás dicas para a execução do planejamento de } \\
\text { cenários eficaz, destacando o crescimento do planejamento por cenários } \\
\text { na área do ensino superior. Os cenários permitem testar a robustez de sua } \\
\text { estratégia atual na luz de diferentes futuros possíveis. Você pode, então, } \\
\text { rever ou repensar a sua estratégia. }\end{array}$ & $\begin{array}{l}\text { Formulação da } \\
\text { estratégia }\end{array}$ \\
\hline 2011 & $\begin{array}{l}\text { Carvalho, Sutter, } \\
\text { Polo e Wright }\end{array}$ & Teórico & $\begin{array}{l}\text { O artigo tem como objetivo trabalhar a importância da construção de } \\
\text { cenários para o processo de Administração Estratégica através de uma } \\
\text { pesquisa bibliográfica. O estudo considera que todas as metodologias } \\
\text { de cenários estudadas trazem sua contribuição para a administração } \\
\text { estratégica. }\end{array}$ & $\begin{array}{l}\text { Formulação e } \\
\text { implementação } \\
\text { da estratégia }\end{array}$ \\
\hline 2012 & $\begin{array}{l}\text { Silva, Spers e } \\
\text { Wright }\end{array}$ & Teórico & $\begin{array}{l}\text { A pesquisa acadêmica sobre elaboração e uso de cenários tem sido } \\
\text { aplicada no Brasil em uma ampla gama de situações, como por exemplo: } \\
\text { o uso dos cenários no planejamento de organizações públicas, privadas e } \\
\text { do terceiro setor; diversidade nas técnicas empregadas; ferramenta capaz } \\
\text { para abordar problemas estratégicos de diferentes naturezas, entre outros. } \\
\text { Segundo os autores, essa diversidade, demonstra uma potencialidade sis- } \\
\text { têmica da ferramenta como plataforma para a formulação estratégica em } \\
\text { ambientes turbulentos, confirmando a importância do uso dos cenários } \\
\text { para a gestão estratégica. }\end{array}$ & $\begin{array}{l}\text { Formulação da } \\
\text { estratégia }\end{array}$ \\
\hline 2013 & $\begin{array}{l}\text { O'Brien e Mea- } \\
\text { dows }\end{array}$ & Empírico & $\begin{array}{l}\text { Para os autores, o uso de cenários pode apoiar o desenvolvimento da } \\
\text { estratégia e permitem melhores decisões estratégicas. }\end{array}$ & $\begin{array}{l}\text { Formulação da } \\
\text { estratégia }\end{array}$ \\
\hline 2013 & $\begin{array}{l}\text { Franco, Meadows } \\
\text { e Armstrong }\end{array}$ & Empírico & $\begin{array}{l}\text { Os autores afirmam que nas últimas décadas emerge a aceitação dos } \\
\text { cenários para apoiar o processo de formulação da estratégia. Como } \\
\text { resultado, o artigo mostra que as oficinas de cenários contribuem para } \\
\text { mudanças de modelos mentais, aprendizagem e para o desenvolvimento } \\
\text { de estratégias robustas. }\end{array}$ & $\begin{array}{l}\text { Formulação da } \\
\text { estratégia }\end{array}$ \\
\hline
\end{tabular}

Figura 6 Contribuição dos cenários para gestão estratégica

Fonte: Elaborado pelos autores.

Conforme apresentado na Figura 6, foram identificados 24 estudos de autores nacionais e internacionais que abordam a contribuição dos cenários para gestão estratégica. Em relação ao tipo de estudo levantado, identificou-se que houve um equilíbrio entre estudos do tipo teórico (13 estudos) e empírico (11 estudos), não havendo uma predominância. Verifica-se assim que a contribuição dos Métodos de Cenários para a gestão estratégica vem sendo investigada tanto no campo teórico como na prática gerencial.
Observa-se, que os estudos de forma geral mencionam a contribuição e relevância dos Métodos de Cenários para a gestão estratégica das organizações, onde a maioria dos estudos (15) cita que os Métodos de Cenários desempenham papel relevante na etapa de formulação da estratégia. Adicionalmente, foram identificados estudos (09) que citam a contribuição e relevância dos Métodos de Cenários no planejamento estratégico, incluindo as etapas de formulação e implementação da estratégia, evidenciando assim a contribuição dos Métodos de Cenários para o alinhamento entre a formulação e implementação 
da estratégia das organizações, conforme mostrado na Figura 6.

No entanto, verifica-se uma baixa incidência de estudos empíricos que abordam a contribuição dos Métodos de Cenários para a formulação e implementação da estratégia (04), destacando-se na Figura 6 os estudos de Franco (2007); Costa et a. (2007); Moritz et al. (2008) e Pillkahn e Sasano (2008), os quais apresentam evidencias da contribuição dos Méto- dos de Cenários aplicados na prática gerencial. Em síntese, os estudos aplicam os Métodos de Cenários integrados à metodologia do planejamento estratégico, reconhecendo sua relevância para formulação e implementação da estratégia.

Por fim, considerando os diversos Métodos de Cenários apresentados, este artigo trás como resultado uma análise crítica das principais características destes, apresentados na Figura 7.

\begin{tabular}{|c|c|c|c|c|c|c|c|c|}
\hline \multirow{2}{*}{ Principais características } & \multicolumn{8}{|c|}{ Métodos } \\
\hline & Cedef & GE & Porter & Godet & GBN & Grum. & Heijd. & Lover. \\
\hline Delimitação do problema & $\boldsymbol{*}$ & $\boldsymbol{*}$ & $\boldsymbol{*}$ & $*$ & $\boldsymbol{*}$ & $\boldsymbol{*}$ & $\boldsymbol{*}$ & $\boldsymbol{*}$ \\
\hline Retrospectiva & $\boldsymbol{*}$ & $\boldsymbol{*}$ & $\boldsymbol{*}$ & $*$ & $\boldsymbol{*}$ & $\boldsymbol{*}$ & $\boldsymbol{*}$ & \\
\hline Identificação das variáveis-chave & $\boldsymbol{*}$ & $\boldsymbol{*}$ & $\boldsymbol{*}$ & $\boldsymbol{*}$ & $\boldsymbol{*}$ & $\boldsymbol{*}$ & $\boldsymbol{*}$ & $\boldsymbol{*}$ \\
\hline Identificação dos atores & & & $\boldsymbol{*}$ & $\boldsymbol{*}$ & $\boldsymbol{*}$ & $\boldsymbol{*}$ & & \\
\hline Análise do ambiente interno & $\boldsymbol{*}$ & $\boldsymbol{x}$ & $*$ & $\boldsymbol{x}$ & $\boldsymbol{*}$ & $\boldsymbol{*}$ & $\boldsymbol{x}$ & $\boldsymbol{*}$ \\
\hline Análise do ambiente externo & $\boldsymbol{*}$ & $\boldsymbol{*}$ & $\boldsymbol{*}$ & $\boldsymbol{*}$ & $*$ & $\boldsymbol{*}$ & $\boldsymbol{*}$ & $\boldsymbol{*}$ \\
\hline Aplicação do Delphi & & $\boldsymbol{*}$ & & $*$ & & $*$ & & \\
\hline Seleção dos indicadores & & $\boldsymbol{*}$ & & & $\boldsymbol{*}$ & & & \\
\hline Utilização de softwares & & $*$ & & $*$ & & $\boldsymbol{*}$ & & \\
\hline Cenários exploratórios & $\boldsymbol{*}$ & $\boldsymbol{*}$ & $\boldsymbol{x}$ & $\boldsymbol{*}$ & $\boldsymbol{*}$ & $\boldsymbol{*}$ & $\boldsymbol{*}$ & $\boldsymbol{*}$ \\
\hline Técnica de impactos cruzados & $\boldsymbol{*}$ & $\boldsymbol{*}$ & $\boldsymbol{*}$ & $\boldsymbol{*}$ & $*$ & $\boldsymbol{x}$ & $\boldsymbol{*}$ & \\
\hline
\end{tabular}

Figura 7 Principais características dos Métodos de Cenários Fonte: Elaborado pela autora.

Verifica-se assim que, todos os métodos relacionados, compartilham cinco principais características, são elas: delimitação do problema; identificação das variáveis-chave; análise do ambiente interno; análise do ambiente externo e o uso de cenários exploratórios. A análise mostra também que alguns métodos apresentam características distintas, o que segundo Loveridge (2009), é difícil argumentar por qualquer método particular, sendo que a principal diferença entre os autores é a ênfase dada a cada etapa do processo.

Assim, a análise considera que todos os Métodos de Cenários apresentados trazem sua contribuição para a gestão estratégica e qualquer método utilizado proporcionará o apoio necessário à formulação e implementação da estratégia da organização.

\section{CONSIDERAÇÕES FINAIS}

Este artigo teve como objetivo analisar a contribuição e relevância dos Métodos de Cenários para o alinhamento entre a formulação e implementação da estratégia por meio de um levantamento teórico do tema 'cenários' relacionado à 'formulação e implementação da estratégia' e 'alinhamento estratégico'. Apesar da baixa incidência de pesquisas que relacionam os temas investigados, foi possível verificar a contribuição dos Métodos de Cenários para a gestão estratégica das organizações, através dos estudos apresentados na Figura 6.

Observa-se que, a maioria dos estudos apresentados (15) citam que os Métodos de Cenários desempenham papel relevante apenas na etapa de formulação da estratégia. Entretanto, destacam-se 
autores como: Fink et al. (2004); Franco (2007); Costa et al. (2007); Moritz et al. (2008) e Pillkahn e Sasano (2008) que afirmam que o uso de cenários pode apoiar tanto o processo de formulação quanto implementação da estratégia. Destacam-se ainda, nove estudos que citam a contribuição dos Métodos de Cenários no planejamento estratégico, onde são incluídas as etapas de formulação e implementação da estratégia, evidenciando também sua contribuição para o alinhamento entre a formulação e implementação da estratégia das organizações.

Adicionalmente, este artigo contribui teoricamente com o gap existente entre formulação e implementação da estratégia e para compreensão das dificuldades de implementação da estratégia, considerando a escassez de pesquisas relativas à problemática de implementação da estratégia nas organizações (ATKINSON, 2006; HUTZSCHENREUTER; KLEINDIENST, 2006; LACERDA, 2009). Contribui ainda com o estado da arte sobre o tema ao apresentar os principais Métodos de Cenários e uma análise crítica das principais características destes.

A partir da análise dos Métodos de Cenários apresentados, percebeu-se que todos compartilham características em comum, e, pelo menos, três fases/ etapas são comuns para todos os métodos, corroborando Godet et al. (2000) quando expõem que não há muitas diferenças nas etapas/passos nos Métodos de Cenários apresentados na literatura. Adicionalmente, Loveridge (2009) afirma que é difícil argumentar por qualquer método em particular, sendo que a principal diferença entre os autores é a ênfase dada a cada etapa do processo. Assim, as organizações podem optar por um método que melhor se adapte a sua realidade e fazer uso durante seu processo estratégico.

Verificou-se ainda que os modelos de alinhamento e implementação apresentados nesta pesquisa (HAMBRICK; CANELLA, 1989; HREBINIAK, 2006; KAPLAN; NORTON, 2008) também podem contribuir para alinhar a formulação e implementação da estratégia nas organizações, evidenciado a partir da interdependência existente entre a formulação e implementação da estratégia, característica comum identificada nos modelos de alinhamento apresentados, ou seja, uma etapa depende da outra, levando ao alinhamento. Em síntese, o levantamento teórico realizado por este artigo conseguiu atingir seu objetivo e responder a questão de pesquisa mostrando através dos estudos apresentados na Figura 6 que os Métodos de Cenários são relevantes e podem contribuir para o alinhamento entre a formulação e implementação da estratégia nas organizações.

Por fim, este estudo contribui para discussão e reflexão sobre a relevância dos Métodos de Cenários para a gestão estratégica organizacional, o qual apresenta carência de estudos, abrindo espaço para o campo das pesquisas acadêmicas, bem como para a prática gerencial. Como limitação do estudo, pode-se citar a falta de uma ferramenta para análise dos dados qualitativos, no entanto, considera-se que essa limitação não invalida o presente estudo. Como sugestões para pesquisas futuras, recomenda-se o uso de uma ferramenta qualitativa para análise dos dados a fim de ampliar a discussão dos resultados. Recomenda-se, também, a continuidade de pesquisas que aborde essa temática, que se apresenta como um desafio para a área da administração. 


\section{REFERÊNCIAS}

AMER, M.; DAIM, T. U.; JETTER, A. A review of scenario planning. Futures, v. 46, p. 23-40, 2013.

ANDREWS, R.; BOYNE, G. A.; LAW, J.; WALKER, R. M. Strategy implementation and public service performance. Administration \& Society, v. 43, n. 6, p. 644-671, 2011.

ATKINSON, H. Strategy implementation: a role for the balanced scorecard? Management Decision, v. 44, n. 10, p. 1441-1460, 2006.

BEATTY, K. C.; QUINN, L. Making strategy real bringing people together toward a common cause. Leadership in Action, v. 27, n. 2, p. 8-11, 2007.

BEER, M., EISENSTAT, R. A. The silent killers of strategy implementation and learning. Sloan Management Review, v. 41, n. 4, p. 29-40, 2000.

BEER, M., EISENSTAT, R. A. How to have an honest conversation about your business strategy. Harvard Business Review, p. 82-89, 2004.

BERTERO, C. O.; VASCONCELOS, F. C. de; BINDER, M. P. Estratégia Empresarial: A Produção Científica Brasileira entre 1991 e 2002. Revista de Administração de Empresas, São Paulo, v. 43, n. 4, p. 48-62, 2003.

BERKHOUT, F.; HERTIN, J. Foresight futures scenarios: developing and appliying a participative strategy planning tool. University of Sussex, UK, Spring, 2002.

CAGNIN, C. Estudos de futuro de CT\&I no Brasil. Parcerias Estratégicas, v.19, p. 49-64, 2014.
CARVALHO, D. E.; SUTTER, M. B.; POLO, E. F.; WRIGHT, J. T. C. Construção de Cenários: apreciação de métodos mais utilizados na administração estratégica. In: ENCONTRO DA ASSOCIAÇÃO NACIONAL DE PÓS-GRADUAÇÃO E PESQUISA EM ADMINISTRAÇÃO, 35., 2011, Rio de Janeiro. Anais..., Rio de Janeiro: ANPAD, 2011.

CHERMACK, T. J.; LYNHAM, S. A.; RUONA, W. E. A. A review of scenario planning literature. Futures Research Quarterly, Summer, 2001.

COSTA, B. K.; FISCHMANN, A. A.; BOAVENTURA, J. M. G.; MUNIZ, C. M. R.; NERY, T. R. Adequação e uso de Cenários prospectivos: um estudo no orgão municipal de turismo de Natal. Turismo - Visão e Ação, Florianópolis, v. 9, n. 1, p. 07-17, 2007.

COCKS, G. Emerging concepts for implementing strategy. The TQM Journal, v. 22, n. 3, p.260-266, 2010 .

DANDIRA, M. Involvement of implementers: missing element in strategy formulation. Business Strategy Series, v.12, n. 1, p. 30-34, 2011.

EEROLA, A. MILES, I. Methods and tools contributing to FTA: A knowledge-based perspective. Futures, v. 43, p.265-278, 2011.

FINK, A.; MARR, B.; SIEBE, A., KUHLE, J.P. The future scorecard: combining external and internal scenarios to create strategic foresight. Decision Management, v. 43, n. 3, p. 360-381, 2005.

FINK, A.; SIEBE, A.; KUHLE, J. P. How scenarios support strategic early warning processes. Foresight, v. 6, n, 3, p. 173-185, 2004.

FRANCO, F. L. Prospectiva Estratégica: uma metodologia para a construção do futuro. Universidade Federal do Rio de Janeiro, 2007. Tese. (Doutorado em Engenharia de Produção) - Universidade Federal do Rio de Janeiro, Rio de Janeiro, 2007. 
FRANCO, L. A.; MEADOWS, M.; ARMSTRONG, S. J. Exploring individual differences in scenario planning workshops: A cognitive style framework. Technological Forecasting \& Social Change, v. 80, p. 723-734, 2013.

FREEDMAN, M. The genius is in the implementation. Journal of Business Strategy, v. 24, n. 2, p. 26-31, 2003.

FUCHS, P. H.; MIFFLIN, K. E.; MILLER, D.; WHITNEY, J. O. Strategic integration: competing in the age of capabilities. California Management Review, v. 42, n.3, p.118-147, 2000.

GANDELLINI, G.; PEZZI, A.; VENANZI, D. Strategy for Action-II: strategy formulation, development, and control. Springer Milan Heidelberg, New York, 2013.

GETZ, G.; JONES, C.; LOEWE, P. Migration management: an approach for improving strategy implementation. Strategy \& Leadership, v. 37, n. 6, p. 18-24, 2009.

GIL, A. C. Como elaborar projetos de pesquisa. $4^{\mathrm{a}}$ Ed., São Paulo: Atlas, 2002.

GODET, M. Integration of scenarios and strategic management. Futures, p. 730-739, 1990.

GODET, M. From anticipation to action. A hand book of stratégie prospective. UNESC Publishing, 1994.

GODET, M. ; ROUBELAT, F. Creating the future the use and misuse of scenarios. Long Range Planning. v. 29, n. 2, p. 164-171, 1996.

GODET, M. Em colaboração com MONTI, R., MEUNIER, F.; ROUBELAT, F. A 'caixa de ferramentas' da prospectiva estratégica. Cadernos do CEPES - Centro de Estudos de Prospectiva e Estratégia, Lisboa, 2000.
GODET, $M$. The art of scenarios and strategic planning: tools and pitfalls. Technological Forecasting and Social Change, v. 65, n. 3, 2000.

GONÇALVES, M. S. Análise dos aspectos internos, do ambiente externo e elaboração de Cenários como base para definição das estratégias. Universidade Federal de Santa Maria, 2011. Mestrado. (Dissertação em Engenharia da Produção) - Universidade Federal de Santa Maria, 2011.

HAMBRICK, D. C; CANNELLA J. R., A. A. Strategy implementation as substance and selling. Academy of Management Executive, v. 3, n. 4, p. 278-285, 1989.

HEIJDEN, K. V. D. Planejamento por Cenários: a arte da conversação estratégica. ${ }^{2}$ ed., Porto Alegre: Bookman, 2009.

HREBINIAK, L. G. Making strategy work: leading effective execution e change. New Jersey: Wharton School Publishing, 2005.

HREBINIAK, L. G. Fazendo a estratégia funcionar: o caminho para uma execução bem-sucedida. Porto Alegre: Bookman, 2006.

HREBINIAK, L. Making strategy work: overcoming the obstacles to effective execution. Evey Business Journal, p. 1-7, 2008.

HUTZSCHENREUTER, T., KLEINDIENST, I. Strategy-Process Research: What have we learned and what is still to be explored. Journal of Management, v. 32, n. 5, p. 673-719, 2006.

JOHNSTON, R. Estudos prospectivos - experiências nacionais de estudos prospectivos: reflexões da Austrália. Elaborado para o Seminário Internacional sobre Estudos Prospectivos em Ciência e Tecnologia. Brasília, 2000. 
JOOSTE, C.; FOURIE, B. The role of strategic leadership in effective strategy implementation: Perceptions of South African strategic leaders. Southern African Business Review, v. 13, n. 3, 2009.

KAPLAN, R. S.; NORTON, D. P. Balanced Scorecard: a estratégia em ação. Rio de Janeiro: Campus. 1997.

KAPLAN, R. S.; NORTON, D. P. Organização orientada para a estratégia: como as empresas que adotam o Balanced Scorecard prosperam no novo ambiente de negócios. Rio de Janeiro: Campus. 2001.

KAPLAN, R. S.; NORTON, D. P. Alinhamento: usando o Balanced Scorecard para criar sinergias corporativas. Rio de Janeiro: Elsevier, 2006.

KAPLAN, R. S.; NORTON, D. P. Using the Balanced Scorecard as a Strategic Management System. Harvard Business Review, p. 1-14, 2007.

KAPLAN, R. S.; NORTON, D. P. A execução premium: a obtenção de vantagem competitiva através do vínculo da estratégia com as operações do negócio. Rio de Janeiro: Elsevier, 2008.

KATHURIA, R.; JOSHI, M. P.; PORTH, S. J. Organizational alignment and performance: past, present and future. Management Decision, v. 45, n. 3, p. 503-517, 2007.

KENNY, J. Strategy and the learning organization: a maturity model for the formation of strategy. The Learning Organization, v. 13, n. 4, p. 353-368, 2006.

LACERDA, D. P. A gestão estratégica em uma universidade privada confessional: compreendendo se e como as intenções transformam-se em ações estratégicas. Universidade Federal do Rio de Janeiro, 2009. Tese. (Doutorado em Engenharia de Produção) - Universidade Federal do Rio de Janeiro, Rio de Janeiro, 2009.
LACERDA, D. P.; CAUlliRAUX, H. M. C. Compreendendo os possíveis fatores que influenciam a transformação das intenções em ações estratégicas: um estudo de caso em uma instituição de ensino superior. In: ENCONTRO DA ASSOCIAÇÃO NACIONAL DE PÓS-GRADUAÇÃO E PESQUISA EM ADMINISTRAÇÃO, 34., 2010, Rio de Janeiro. Anais..., Rio de Janeiro: ANPAD, 2010.

LI, Y.; GUOHUI, S.; EPPLER, M. J. Making Strategy Work: a literature review on the factors influencing strategy implementation. ICA Working Paper 2, p.1-46, 2008.

LOVERIDGE, D. Foresight: the art and science of anticipating the future. New York: Routledge, 2009.

LOVERIDGE, D.; SARITAS, O. Ignorance and uncertainty: influences on future-oriented technology analysis. Technology Analysis \& Strategic Management, v.24, n.8, p.753-767, 2012.

MARTIN, R. L. The execution trap. Harvard Business Review, v. 88, n. 7-8, p. 64-71, 2010.

MARCIAL, E. C.; GRUMBACH, R. J. S. Cenários prospectivos: como construir um futuro melhor. 5ªed. Rio de Janeiro: Editora FGV, 2008.

MIETZNER, D.; REGER, G. Scenario Approaches History, Differences, Advantages and Disadvantages. In: EU-US SEMINAR: NEW TECHNOLOGY FORESIGHT, FORECASTING \& ASSESSMENT METHODS, Seville 13-14 May 2004.

MILES, R. E.; SNOW, C. C. Fit, Failure and the Hall of Fame. California Management Review, v. 26, n. 3, p. 10 - 28, 1984.

MINTZBERG, H.; AHLSTRAND, B.; LAMPEL, J. Safári de estratégia: um roteiro pela selva do planejamento estratégico. Porto Alegre: Bookman. 2010.

MINTZBERG, $\mathrm{H}$. The fall and rise of strategic planning. Harvard Business Review, v.72, n.1, p. 107-114, 1994. 
MINTZBERG, H. Ascensão e queda do planejamento estratégico. Porto Alegre: Bookman. 2004.

MORITZ, G. O.; PEREIRA, M. F. Planejamento de Cenários: a evolução do pensamento prospectivo. Revista de Ciências da Administração, Florianópolis, v. 7, n. 13, 2005.

MORITZ, G. O.; NUNER, R.; PEREIRA, M. F. Os métodos de prospecção de Cenários e sua aplicação nas organizações: um estudo de caso no período 1998-2008. FACES R. Adm, Belo Horizonte, v. 7, n. 2, p. $68-83,2008$.

NOBLE, C. H. Building the strategy implementation network. Business Horizons, v. 42, n. 6, p. 19-28, 1999a.

NOBLE, C. H. The eclectic roots of strategy implementation research. Journal of Business Research, v. 45 , n. 2 , p. $119-134,1999$ b.

OKUMUS, F. A framework to implementing strategies in organizations. Management Decisions, v. 41, n. 9, p.871-882, 2003.

OGILVY J.; SCHWARTZ, P. Plotting Your Scenarios. Califórnia: Global Business Network, 2004.

O'BRIEN, F. A.; MEADOWS, M. Scenario orientation and use to support strategy development. Technological Forecasting \& Social Change, v. 80, p. 643-656, 2013.

PILLKAHN, U. Using trends and scenarios as tools for strategy development. Publicis Corporate Publishing, Erlangen, Germany, 2008.

\section{PILLKAHN, U. SASANO, S. Scenario development} 2.0. In: Third International Seville Seminar on Future-Oriented Technology Analysis (FTA), Seville 16-17 October 2008.
PORTER, A. L.; CLAR, G.; COATES, J. F.; CUHLS, k.; CUNNINGHAM, S. W.; DUCATEL, k.; DUIN, P. V. D.; GEORGEHIOU, L.; GORDON, T.; LINSTONE, H.; MARCHAU, V.; MASSARI, G.; MILES, I.; MOGEE, M.; SALO, A.; SCAPOLO, F.; SMITS, R.; THISSEN, W. Technology futures analysis: Toward integration of the field and new methods (Technology Futures Analysis Methods Working Group). Technological Forecasting \& Social Change, v.71, p. 287-303,2004.

PORTER, M. E. Vantagem competitiva: criando e sustentando um desempenho superior. Rio de Janeiro: Campus, 1992.

PRIETO, V. C.; CARVALHO, M. M.; FISCHMANN, A. A. Análise comparativa de modelos de alinhamento estratégico. Produção, São Paulo, v. 19, n. 2, p. 317-331, 2009.

PRIETO, V. C. Impacto do alinhamento da estratégia de negócios sobre o desempenho. Escola Politécnica da Universidade de São Paulo. Tese. (Doutorado em Engenharia de Produção) - Escola Politécnica da Universidade de São Paulo, São Paulo, 2011.

RAPS, A. Implementing strategy. Strategic finance, p. 49-54, 2004.

RATCLIFFE, J. Scenario building: a suitable method for strategic property planning? Futures Academy, Dublin Institute of Technology, 2000.

RICHARDS, L.; O'SHEA, J.; CONNOLLY, M. Managing the concept of strategic change within a higher education institution: the role of strategic and scenario planning techniques. Strategic Change, v. 13, p. 345-359, 2004.

ROCHA, H. M. Cenários prospectivos: ferramentas estratégicas para obtenção e manutenção da vantagem competitiva das organizações. Revista Eletrônica de Ciência Administrativa - RECADM, Campo Largo, v. 3, n. 2, p. 2-15, 2004. 
ROCHA, H. M.; OLIVEIRA, U. R. Cenários prospectivos para a o gerenciamento de riscos e incertezas: uma ferramenta a ser explorada pelas organizações. In: Simpósio de Engenharia de Produção, 13., 2006, Bauru. Anais..., Bauru: SIMPEP, 2006.

ROSE, W. R.; CRAY, D. The role of context in the transformation of planned strategy into implemented strategy. International Journal of Business Management \& Economic Research, v. 4, n. 3, p. 721-737, 2013.

SANTOS, A. B. A. Um modelo integrador para formulação de estratégias múltiplas: contribuição da análise prospectiva. Pontifícia Universidade Católica do Rio de Janeiro, 2011. Tese. (Doutorado em Engenharia de Produção) - Pontifícia universidade católica do Rio de Janeiro, Rio de Janeiro, 2011.

SAYERS, N. Maximising the effectiveness of a scenario planning process Tips for scenario planners in higher education. Perspectives, v. 15, n. 1, p.1418, 2011.

SEMLER, S. W. Systematic agreement: a theory of organizational alignment. Human Resource Development Quarterly, v. 8, n. 1, p.23-40, 1997.

SILVA, A. T. B.; SPERS, R. G.; WRIGHT, J. T. C. Elaboração de Cenários na gestão estratégica das organizações: um estudo bibliográfico. Revista de Ciências da Administração, Florianópolis, v. 14, n. 32, p.21-34, 2012.

SIGGELKOW, N. Change in the presence of fit: The rise, the fall, and the renaissance of Liz Claiborne. Academy of Management Journal, v. 44, n. 4, 2001.
VARUM, C. A.; MELO, C. Directions in scenario planning literature - A review of the past decades. Futures, v. 42, p. 355-369, 2010.

VENKATRAMAN, N.; CAMILLUS, J. C. Exploring the concept of 'fit' in strategic management. Academy of Managemeni Review, v. 9, n. 3, p. 513 $525,1984$.

VENKATRAMAN, N.; PRESCOTT, J. E. Environment-Strategy Coalignment: An Empirical Test of Its Performance Implications. Strategic Management Journal, v. 11, n.1, p. 1-23, 1990.

WACK, P. Scenarios: Unchartered Waters Ahead. Harvard Business Review, v. 63, n. 5, p.72-89, 1985a.

WRIGHT, J. T. C.; SILVA, A. T. B.; SPERS, R. G. Prospecção de Cenários: uma abordagem plural para o futuro do Brasil em 2020. Revista IberoAmericana de Estratégia - RIAE, São Paulo, v. 9, n. 1, p. 56-76, 2010.

YUKL, G.; LEPSINGER, R. Getting it done four ways to translate strategy into results. LIA, v. 27, n. 2, p. 03-07, 2007.

ZAJAC, E. J.; KRAATZ, M. S.; BRESSER, R. K. F. Modeling the dynamics of strategic fit: A normative approach to strategic change. Strategic Management Journal, v. 21, n. 4, p.429-453, 2000. 